Бычкова Гульфира Мубараковна, к.э.н., доцент, Ангарский государственный технический университет, e-mail: gulfira_agta@mail.ru

ОСОБЕННОСТИ ФАКТОРНОГО АНАЛИЗА В ОПТОВОЙ ТОРГОВЛЕ

Bychkova G.M.

\title{
FEATURES OF FACTOR ANALYSIS IN WHOLESALE TRADE
}

Аннотация. Исследована возможность адаптации классической методики факторного анализа прибыли от продаж в сфере производства к сфере оптовой торговли.

Ключевые слова: факторный анализ, прибыль от продаж, факторы, коммерческие расходы, система учета.

Abstract. The possibility of adapting the classical method of factor analysis of profit from sales in the field of production to the field of wholesale trade is investigated.

Keywords: factor analysis, profit from sales, factors, business expenses, accounting system.

Факторный анализ прибыли заключается в выявлении различных факторов, оказывающих влияние на сумму получаемой прибыли или уровень рентабельности, и определении их влияния на результативный показатель. Традиционная методика анализа ориентирована на сферу производства и оказания услуг. Источниками информации для анализа являются Отчет о финансовых результатах (ОФР), данные бухгалтерского и управленческого учета.

Прибыль от продаж является основной составляющей бухгалтерской и чистой прибыли. Именно она контролируется в первую очередь. Остается не до конца решенной проблема адаптации методики факторного анализа прибыли от продаж для оптовой торговли. Что же является сдерживающим моментом. Во-первых, особенности учета и формирования отчетности в оптовой торговле не позволяют разделить факторы, на характеризующие непосредственно процесс торговли и на характеризующие управление этим процессом. Во-вторых, упрощенная фрорма отчетности в малом бизнесе, в том числе и в оптовой торговле создает ограничения в использовании факторного анализа. Все сказанное выше обусловило актуальность темы настоящего исследования, его цель и задачи, теоретическую и практическую значимость.

Цель исследования - адаптировать методику факторного анализа прибыли от продаж в сорере производства к оптовой торговле.

Для достижения цели исследования поставлены и решены следующие задачи:

- исследованы и систематизированы ограничения, сдерживающие внедрение фракторного анализа прибыли от продаж в оптовую торговлю;

- разработаны рекомендации по внесению изменений в бухгалтерский учет и отчетность, позволяющие внедрить факторный анализ прибыли от продаж в оптовую торговлю; 
- разработана аналитическая модель проведения фракторного анализа прибыли от продаж в оптовой торговле, способствующая выявлению резервов повышения ее прибыльности и эффективности;

- апробирована разработанная аналитическая модель, и подтверждена возможность ее использования в процессе проведения фракторного анализа прибыли от продаж в оптовой торговле.

Объект исследования - процессы формирования прибыли от продаж различных групп товаров, реализуемых оптом, а также фракторы, влияющие на ее величину. Предмет исследования - совокупность процессов отражения в учете и отчетности показателей, участвующих в расчете прибыли от продаж в оптовой торговле.

Рассмотрим и систематизируем основные процессы бухгалтерского учета и формирования отчетности, сдерживающие внедрение фракторного анализа прибыли от продаж в оптовую торговлю в малом бизнесе и представим их в таблице 1.

Основные недостатки упрощенной формы отчетности для малого бизнеса в оптовой торговле:

- не фрормируется показатель 2100 «Валовая прибыль (убыток)» - это показатель суммы торговой наценки, за счет которой функционирует весь бизнес;

- не формируется показатель 2200 «Прибыль (убыток) от продаж», характеризующий основную деятельность;

- в показателе 2120 «Расходы по обычной деятельности» объединены покупная стоимость товара (счет 41) и все расходы, связанные с его реализацией (счет 44) [3].

В системе бухгалтерского учета все расходы, связанные с функционированием торговли, отражаются на счете 44 «Коммерческие расходы», в то время как в производстве идет четкое разделение расходов, связанных с выпуском продукции, расходов, связанных с управлением и с продвижением товара, что позволяет оценить «вклад» каждого вида расходов в прибыль от продаж [2].

Что предлагается изменить в учетной системе организации оптовой торговли в малом бизнесе:

1. Отказаться от упрощенной фрормы отчетности и фрормировать «контрольные», значимые для анализа показатели, тем более, что право выбора в этом случае за бизнесом.

2. Ввести на счете 44 «Коммерческие расходы» аналитический учет - два субсчета:

2.1 счет 44.1 - коммерческие расходы, связанные непосредственно с процессом торговли, например, оплата труда продавцов, менеджеров по продаже, содержание торговых площадей и т.д. (КР1); 
2.2 счет 44.2 - коммерческие расходы, связанные с управлением процессом торговли. Это могут быть расходы, связанные с выбором поставщиков товара, обоснованием ценовой политики, выбором места дислокации бизнеса и оплатой труда управленческого персонала в торговле $\left(\mathrm{KP}_{2}\right)$.

Таблица 1

Сравнение состава строк полного в сфрере производства и упрощенного в торговле «Отчета о финансовых результатах»

\begin{tabular}{|c|c|c|c|}
\hline Строка ОФР & $\begin{array}{c}\text { Порядок } \\
\text { формирования } \\
\text { показателя }\end{array}$ & Строка ОФР & $\begin{array}{c}\text { Порядок } \\
\text { формирования } \\
\text { показателя }\end{array}$ \\
\hline \multicolumn{2}{|c|}{ полного отчета в производстве } & \multicolumn{2}{|c|}{ упрощенного отчета в торговле } \\
\hline $\begin{array}{l}2110 \text { «Выруч- } \\
\text { ка» }\end{array}$ & $\begin{array}{l}\text { Разница между кредито- } \\
\text { вым оборотом субсчета } \\
\text { «Выручка» счета } 90 \text { и де- } \\
\text { бетовыми оборотами суб- } \\
\text { счетов «НДС», «Акцизы», } \\
\text { «Вывозные таможенные } \\
\text { пошлины» (счет 90) }\end{array}$ & $\begin{array}{l}2110 \text { «Вы- } \\
\text { ручка» }\end{array}$ & $\begin{array}{l}\text { Разница между кредито- } \\
\text { вым оборотом субсчета } \\
\text { «Выручка» счета 90 и } \\
\text { дебетовыми оборотами } \\
\text { субсчетов «НДС», «Ак- } \\
\text { цизы», «Вывозные та- } \\
\text { моженные пошлины» } \\
\text { (счет 90) }\end{array}$ \\
\hline $\begin{array}{l}2120 \text { «Себе- } \\
\text { стоимость } \\
\text { продаж» }\end{array}$ & $\begin{array}{l}\text { Дебетовый оборот по суб- } \\
\text { счету «Себестоимость } \\
\text { продаж» счета } 90 \text { в корре- } \\
\text { спонденции со счетами } \\
20,43 \text { и } 45\end{array}$ & \multirow{3}{*}{$\begin{array}{lr}2120 & \text { «ас- } \\
\text { ходы } & \text { по } \\
\text { обычной } \\
\text { яе-- } \\
\text { ятельно- } \\
\text { сти» }\end{array}$} & $\begin{array}{ll}\text { Дебетовый оборот по } \\
\text { субсчету } \\
\text { мость продаж» счета } 90 \\
\text { в корреспонденции со } \\
\text { счетом } 41\end{array}$ \\
\hline $\begin{array}{l}2210 \text { «Ком- } \\
\text { мерческие } \\
\text { расходы» }\end{array}$ & $\begin{array}{l}\text { Дебетовый оборот суб- } \\
\text { счета «Себестоимость } \\
\text { продаж» счета } 90 \text { в корре- } \\
\text { спонденции со счетом } 44\end{array}$ & & $\begin{array}{l}\text { Дебетовый оборот суб- } \\
\text { счета «Себестоимость } \\
\text { продаж» счета } 90 \text { в кор- } \\
\text { респонденции со счетом } \\
44\end{array}$ \\
\hline $\begin{array}{l}2220 \text { «Управ- } \\
\text { ленческие } \\
\text { расходы» }\end{array}$ & $\begin{array}{l}\text { Дебетовый оборот суб- } \\
\text { счета «Себестоимость } \\
\text { продаж» счета } 90 \text { в корре- } \\
\text { спонденции со счетом } 26\end{array}$ & & Не фрормируется \\
\hline $\begin{array}{l}2100 \text { «Вало- } \\
\text { вая прибыль } \\
\text { (убыток)» }\end{array}$ & $\begin{array}{l}\text { Разница между строками } \\
2110 \text { и } 2120\end{array}$ & \multicolumn{2}{|c|}{ Не фрормируется } \\
\hline $\begin{array}{l}2200 \text { «При- } \\
\text { быль (убыток) } \\
\text { от продаж» }\end{array}$ & $\begin{array}{l}\text { Разность строки } 2110 \text { и } \\
\text { строк } 2120,2210 \text { и } 2220\end{array}$ & \multicolumn{2}{|c|}{ Не фрормируется } \\
\hline
\end{tabular}

Bce предлагаемые изменения можно отразить в учетной политике организации, и они позволят, по нашему мнению, использовать методику факторного анализа прибыли от продаж и в торговле.

Апробируем методику факторного анализа прибыли от продаж для оптовой торговли. Для этого построим предлагаемую аналитическую модель на примере условного предприятия, используя при этом ППП Excel, который позволяет моделировать ситуацию и значительно экономит время, затрачиваемое на расчеты. Сформируем фрагмент ОФР, содержащий необходимые для анализа показатели для оптовой торговли, после внедрения предлагаемых рекомендаций в таблице 2. 
Отчет о фринансовых результатах ООО «Ромашка» (фррагмент)

\begin{tabular}{|c|c|c|c|c|c|c|c|c|}
\hline $\begin{array}{l}\text { № } \\
\Pi / \Pi\end{array}$ & $\begin{array}{c}\text { Наименование } \\
\text { показателя ОФР }\end{array}$ & $\begin{array}{l}\text { Код } \\
\text { строки }\end{array}$ & $\begin{array}{c}\text { За от- } \\
\text { четный } \\
\text { период, } \\
\text { тыс. руб. }\end{array}$ & $\begin{array}{c}\text { За анало- } \\
\text { гичный пе- } \\
\text { риод про- } \\
\text { шлого года, } \\
\text { тыс. руб. }\end{array}$ & $\begin{array}{c}\text { Абсолютное } \\
\text { отклонение } \\
( \pm), \text { тыс. } \\
\text { руб. }\end{array}$ & $\begin{array}{c}\text { Уровень к } \\
\text { выручке в } \\
\text { отчетном } \\
\text { периоде, } \\
\%\end{array}$ & $\begin{array}{c}\text { Уровень в } \\
\text { выручке в } \\
\text { базисном } \\
\text { периоде, } \\
\text { \% }\end{array}$ & $\begin{array}{c}\text { Отклоне- } \\
\text { ние уров- } \\
\text { ня, \% }\end{array}$ \\
\hline 1 & $\begin{array}{l}\text { Выручка от продажи } \\
\text { (В) (счет 90.1) }\end{array}$ & 2110 & 106969 & 99017 & 7952 & 100,00 & 100,00 & 0,00 \\
\hline 2 & $\begin{array}{l}\text { Покупная стоимость } \\
\text { товаров (C) (счет 41) }\end{array}$ & 2120 & 69744 & 70203 & -459 & 65,20 & 70,90 & $-5,70$ \\
\hline 3 & $\begin{array}{l}\text { Валовая } \text { прибыль } \\
\text { (ВП) (стр. } 2110 \text { - стр. } \\
2120) \\
\end{array}$ & 2100 & 37225 & 28814 & 8411 & 34,80 & 29,10 & 5,70 \\
\hline 4 & $\begin{array}{l}\text { Коммерческие расхо- } \\
\text { ды }\left(\mathrm{KP}_{1}\right)(\text { (сч. } 44.1)\end{array}$ & 2210 & 5562 & 594 & 4968 & 5,20 & 0,60 & 4,60 \\
\hline 5 & $\begin{array}{l}\text { Коммерческие расхо- } \\
\text { ды }\left(\mathrm{KP}_{2}\right)(\text { сч. } 44.2)\end{array}$ & 2220 & 3102 & 198 & 2904 & 2,90 & 0,20 & 2,70 \\
\hline 6 & $\begin{array}{l}\text { Прибыль от продаж } \\
\text { (Пп) (стр. } 2100 \text { - стр. } \\
2210 \text { - стр. 2220) }\end{array}$ & 2200 & 28561 & 28022 & 539 & 26,70 & 28,30 & $-1,60$ \\
\hline
\end{tabular}


Прибыль от продаж находится под непосредственным влиянием объема и структуры продаж, цены реализации, себестоимости единицы продукции. Мы воспользуемся методикой фракторного анализа прибыли от продаж, достаточно полно представленной в источниках [1]. Адаптируем показатели-фракторы к оптовой торговле.

На прибыль от продаж влияют следующие фракторы:

- количество проданного товара (объем продаж);

- цена реализации;

- уровень покупной стоимости проданного товара в выручке (покупная стоимость проданного товара на 1 руб. выручки);

- уровень коммерческих расходов в выручке (коммерческие расходы КР 1 на 1 руб. выручки);

- уровень коммерческих расходов в выручке (коммерческие расходы КР2 на 1 руб. выручки).

Выполним дополнительные расчеты показателей, необходимых для перехода к факторному анализу прибыли от продаж (таблица 3).

Таблица 3

Расчет показателей для фракторного анализа прибыли от продаж

\begin{tabular}{|c|l|c|c|}
\hline № п/п & \multicolumn{1}{|c|}{ Показатели } & Ед. изм. & Оценка \\
\hline 1 & $\begin{array}{l}\text { Прирост цен реализации товаров в отчетном } \\
\text { периоде по сравнению с базисным (в среднем) }\end{array}$ & \% & 19,00 \\
\hline 2 & Индекс цены [(100 + стр. 1) : 100] & - & 1,19 \\
\hline 3 & Выручка от продажи в отчетном периоде & тыс. руб. & 106969 \\
\hline 4 & $\begin{array}{l}\text { Выручка от продажи в прошедшем (базисном) } \\
\text { периоде }\end{array}$ & тыс. руб. & 99017 \\
\hline 5 & $\begin{array}{l}\text { Выручка от продажи в отчетном периоде в со- } \\
\text { поставимых ценах (стр. 3: стр. 2) }\end{array}$ & тыс. руб. & 89889,92 \\
\hline 6 & $\begin{array}{l}\text { Изменение выручки от продажи в отчетном пе- } \\
\text { риоде по сравнению с прошедшим за счет из- } \\
\text { менения цены (стр. 3 - стр. 5) }\end{array}$ & тыс. руб. & 17079,08 \\
\hline 7 & $\begin{array}{l}\text { Изменение выручки от продажи в отчетном пе- } \\
\text { риоде по сравнению с прошедшим за счет из- } \\
\text { менения количества проданных товаров (стр. 5 } \\
\text {-стр. 4) }\end{array}$ & тыс. руб. & -9 127,08 \\
\hline 8 & $\begin{array}{l}\text { Итого абсолютное отклонение выручки (стр. 6 + } \\
\text { стр. 7) }\end{array}$ & тыс. руб. & 7952,00 \\
\hline
\end{tabular}

Сокращение количества реализуемых товаров привело к уменьшению выручки в отчетном периоде на 9 127,08 тыс. руб., а общий прирост выручки (+7 952 тыс. руб.) получился за счет повышения цен на 19\%. В данном случае прирост качественного фрактора - цены $(+17079,08)$ перекрыл негативное влияние количественного фактора.

Выполним расчет влияния фактора «цена» на прибыль от продаж в таблице 4. 
Расчет влияния фрактора «цена» на прибыль от продаж

\begin{tabular}{|c|l|c|c|}
\hline № п/п & \multicolumn{1}{|c|}{ Показатели } & Ед. изм. & Оценка \\
\hline 1 & Выручка от продажи в прошедшем периоде & тыс. руб. & 99017 \\
\hline 2 & Прибыль от продаж в прошедшем периоде & тыс. руб. & 28022 \\
\hline 3 & $\begin{array}{l}\text { Рентабельность продаж в базисном периоде (стр. } \\
2: \text { стр. 1 × 100) }\end{array}$ & \% & 28,30 \\
\hline 4 & Изменение выручки за счет фрактора «цена» & тыс. руб. & 17079,08 \\
\hline 5 & $\begin{array}{l}\text { Влияние фрактора «цена» на прибыль от продаж } \\
\text { (стр. 4 × стр. 3: 100) }\end{array}$ & тыс. руб. & 4833,41 \\
\hline
\end{tabular}

Таким образом, прирост цен на продукцию в отчетном периоде по сравнению с прошедшим периодом в среднем на 19\% привел к увеличению суммы прибыли от продаж на 4 833,41 тыс. руб.

Выполним расчет влияния фактора «количество проданного товара» на прибыль от продаж (таблица 5).

Таблица 5

Расчет влияния фрактора «количество проданного товара» на прибыль от продаж

\begin{tabular}{|c|l|c|c|}
\hline № п/п & \multicolumn{1}{|c|}{ Показатели } & Ед. изм. & Оценка \\
\hline 1 & $\begin{array}{l}\text { Рентабельность продаж в базисном периоде (см. } \\
\text { табл. 4) }\end{array}$ & \% & 28,30 \\
\hline 2 & $\begin{array}{l}\text { Изменение выручки за счет фрактора «количество } \\
\text { проданной продукции» }\end{array}$ & тыс. руб. & -9 127,08 \\
\hline 3 & $\begin{array}{l}\text { Влияние фрактора «количество проданной продук- } \\
\text { ции» на прибыль от продаж (стр. 1 × стр. 2:100) }\end{array}$ & тыс. руб. & -2 582,96 \\
\hline
\end{tabular}

Таким образом, влияние количества проданного товара получилось отрицательным, т.е. сокращение в отчетном периоде объема полученной выручки в сопоставимых ценах привело к сокращению прибыли от продаж на 2 582,98 тыс. руб., потому что на выручку, помимо цены влияет и количество реализуемого товара. Выполним расчет влияния фактора «покупная стоимость товара» на прибыль от продаж (таблица 6).

Таблица 6

Расчет влияния фрактора «покупная стоимость товара» на прибыль от продаж

\begin{tabular}{|c|l|c|c|}
\hline № п/п & \multicolumn{1}{|c|}{ Показатели } & Ед. изм. & Оценка \\
\hline 1 & Выручка от продаж в отчетном периоде & тыс. руб. & 106969 \\
\hline 2 & Выручка от продаж в базисном периоде & тыс. руб. & 99017 \\
\hline 3 & Покупная стоимость товара в отчетном периоде & тыс. руб. & 69744 \\
\hline 4 & Покупная стоимость товара в базисном периоде & тыс. руб. & 70203 \\
\hline 5 & $\begin{array}{l}\text { Уровень покупной стоимости проданного товара в } \\
\text { выручке от продаж в базисном периоде (стр. 4 : } \\
\text { стр. 2 × 100) }\end{array}$ & \% & 70,90 \\
\hline
\end{tabular}


Окончание таблицы 6

\begin{tabular}{|c|l|c|c|}
\hline № п/п & \multicolumn{1}{|c|}{ Показатели } & Ед. изм. & Оценка \\
\hline 6 & $\begin{array}{l}\text { Уровень покупной стоимости проданного товара в } \\
\text { выручке от продаж в отчетном периоде (стр. 3 : } \\
\text { стр. } 1 \text { × 100) }\end{array}$ & $\%$ & 65,20 \\
\hline 7 & $\begin{array}{l}\text { Влияние фрактора «покупная стоимость проданно- } \\
\text { го товара» на прибыль от продаж [стр. 1 × (стр. 6 } \\
- \text { стр. 5)] : 100 }\end{array}$ & тыс. руб. & -6 096,97 \\
\hline
\end{tabular}

При анализе нужно быть внимательным, так как расходы - это фракторы обратного влияния на прибыль от продаж. Снижение покупной стоимости проданного товара в отчетном периоде на 459 тыс. руб. и снижение ее удельного веса в выручке от продаж на 5,7 \% привело к увеличению прибыли от продаж на 6 096,97 тыс. руб.

Выполним расчет влияния фактора «коммерческие расходы КР 1 » на прибыль от продаж (таблица 7).

Таблица 7

Расчет влияния фрактора «коммерческие расходы КР 1 » на прибыль от продаж

\begin{tabular}{|c|l|c|c|}
\hline № п/п & \multicolumn{1}{|c|}{ Показатели } & Ед. изм. & Оценка \\
\hline 1 & Выручка от продаж в отчетном периоде & тыс. руб. & 106969 \\
\hline 2 & $\begin{array}{l}\text { Уровень коммерческих расходов КР } 1 \text { в выручке от } \\
\text { продаж в базисном периоде }\end{array}$ & $\%$ & 0,60 \\
\hline 3 & $\begin{array}{l}\text { Уровень коммерческих расходов КР } 1 \text { в выручке от } \\
\text { продаж в отчетном периоде }\end{array}$ & $\%$ & 5,20 \\
\hline 4 & $\begin{array}{l}\text { Влияние орактора «коммерческие расходы КР } 1 \text { на } \\
\text { прибыль от продаж [стр. 1 × (стр. 3 - стр. 2)] : 100 }\end{array}$ & тыс. руб. & 4920,30 \\
\hline
\end{tabular}

Увеличение коммерческих расходов КР 1 в отчетном периоде по сравнению с базисным на 4968 тыс. руб., а также увеличение их удельного веса в выручке от продаж на 4,6\% (5,2\% - 0,6\% = 4,6\%) привело к снижению прибыли от продаж на 4 920,30 тыс. руб.

Выполним расчет влияния фрактора «коммерческие расходы КР $\mathrm{P}_{2}$ на прибыль от продаж (таблица 8).

Таблица 8

Расчет влияния фрактора «коммерческие расходы КР 2 » на прибыль от продаж

\begin{tabular}{|c|l|c|c|}
\hline № п/п & \multicolumn{1}{|c|}{ Показатели } & Ед. изм. & Оценка \\
\hline 1 & Выручка от продаж в отчетном периоде & тыс. руб. & 106969 \\
\hline 2 & $\begin{array}{l}\text { Уровень коммерческих расходов КР в выручке от } \\
\text { продаж в базисном периоде }\end{array}$ & $\%$ & 0,20 \\
\hline 3 & $\begin{array}{l}\text { Уровень коммерческих расходов КР } \\
\text { продаж в отчетном периоде }\end{array}$ & выруке от & 2,90 \\
\hline 4 & $\begin{array}{l}\text { Влияние фрактора «коммерческие расходы КР } \\
\text { прибыль на }\end{array}$ & тыс. руб. & 2888,10 \\
\hline
\end{tabular}


Увеличение коммерческих расходов КР2 в отчетном периоде по сравнению с базисным на 2904 тыс. руб., а также увеличение их удельного веса в выручке от продаж на 2,7\% привело к снижению прибыли от продаж на 2888,10 тыс. руб.

Выполним сводный анализ влияния фракторов на прибыль от продаж в оптовой торговле и представим его в таблице 9.

Таблица 9

Сводный анализ влияния фракторов на прибыль от продаж

\begin{tabular}{|c|c|c|c|}
\hline № $ா / п$ & Показатели-фракторы & $\begin{array}{l}\text { Оценка, } \\
\text { тыс. руб. }\end{array}$ & $\begin{array}{c}\text { Удельный вес } \\
\text { вклада каждого } \\
\text { фактора в } \\
\text { результирующий } \\
\text { показатель, \% }\end{array}$ \\
\hline 1 & Изменение цен на реализованный товар & 4833,41 & 896,74 \\
\hline 2 & $\begin{array}{l}\text { Изменение количества } \text { реализованного } \\
\text { товара }\end{array}$ & $-2582,98$ & $-479,22$ \\
\hline 3 & $\begin{array}{l}\text { Изменение покупной стоимости реализо- } \\
\text { ванных товаров }\end{array}$ & 6096,97 & 1131,17 \\
\hline 4 & Изменение коммерческих расходов $\left(\mathrm{KP}_{1}\right)$ & $-4920,30$ & $-912,86$ \\
\hline 5 & Изменение коммерческих расходов $\left(\mathrm{KP}_{2}\right)$ & $-2888,10$ & $-535,83$ \\
\hline 6 & $\begin{array}{l}\text { Общее влияние фракторов на изменение } \\
\text { прибыли от продаж (стр. } 1 \text { + стр. } 2+\text { стр. } 3 \\
+ \text { стр. } 4 \text { + стр. } 5 \text { ) }\end{array}$ & 539,00 & 100,00 \\
\hline
\end{tabular}

Таким образом, анализ динамики прибыли от продаж, представленный в таблице 2, позволяет увидеть только абсолютное отклонение - общее увеличение прибыли от продаж на 539 тыс. руб. Предлагаемый подход - вклад каждого из анализируемых показателей-фракторов в изменение прибыли от продаж.

Можно предположить, что положительное влияние фактора «цена» и фактора «покупная стоимость товара» явилось результатом усилий управленческого персонала, но в то же время привело к увеличению коммерческих расходов К2. Результат можно оценить, как положительный, т.к. «вклад» управленцев выше, чем расходы, связанные с процессом управления. Уменьшение количества реализованного товара и повышение расходов на его реализацию $\left(\mathrm{KP}_{1}\right)$ может быть следствием снижения эффрективности работы персонала, непосредственно продающего товар. Однозначные выводы в анализе получить достаточно сложно, но уровень обоснованности решений становится выше. Бизнесу можно рекомендовать выполнить классификацию расходов с точки зрения того, кто и какие расходы контролирует, и увязать систему мотивации персонала в оптовой торговле с величиной этих расходов. 
Поставленные в исследовании цели выполнены, задачи решены. Разработаны предложения по внесению изменений в учетно-аналитическую систему организаций оптовой торговли, позволившие адаптировать и апробировать методику факторного анализа прибыли от продаж к сфере оптовой торговли. По всем показателям приведены алгоритмы расчетов, что упростит процесс внедрения предложений в практику.

Традиционная методика факторного анализа прибыли от продаж в сфрере производства продукции и оказания услуг адаптирована к сфере оптовой торговли, благодаря качественным изменениям в системе учета коммерческих расходов и формирования полной отчетности в малом бизнесе, что расширяет сферу применения методики и способствует повышению качества управления торговым процессом.

\section{ЛИТЕРАТУРА}

1. Войтоловский Н.В. Экономический анализ. Основы теории. Комплексный анализ деятельности организации / Н.В. Войтоловский, А.П. Калинина, И.И. Мазурова. М.: Юрайт, 2014. 548 с.

2 Кондраков Н.П. Бухгалтерский (финансовый, управленческий) учет: учебник / Н.П. Кондраков. М.: Проспект, 2018. 512 с.

3 Ровенских В.А., Слабинская И.А. Бухгалтерская (финансовая) отчетность: учебник / В.А. Ровенских, И.А. Слабинская. М.: Дашков и К, 2013. 364 с. 